\title{
Healthcare Practitioner's Views on the Teddy Bear Hospital (TBH) by IMACATS in Malaysia
}

\author{
Aneesa Abdul Rashid ${ }^{1}$, Cheong Ai Theng ${ }^{1}$, Ranita Hisham Shanmugam ${ }^{2}$, \\ Nurainul Hana Shamsuddin ${ }^{1}$, Dalila Roslan ${ }^{3}$ \\ ${ }^{1}$ Jabatan PerubatanKeluarga, FakultiPerubatan dan Sains Kesihatan, UPM ${ }^{2}$ UM Library, \\ University of Malaya, Jalan Universiti, 50603 Kuala Lumpur, ${ }^{3}$ Ministry of Health, 62000 \\ Putrajaya, Wilayah Persekutuan Putrajaya, Malaysia \\ DOI: http://dx.doi.org/10.31344/ijhhs.v5i0.309
}

Introduction: This is a part of a bigger study entitled "Exploring the Views of Healthcare Practitioners on the Teddy Bear Hospital (TBH) as a Personal Safety Module Towards Prevention of Child Sexual Abuse (CSA): A Qualitative Study". TBH is a make-believe-play hospital utilising soft toys to demonstrate a pretend clinical setting with the aim to educate children on health issues. Studies has shown its effectiveness and reducing anxiety towards the hospital setting and increasing health-related knowledge. IMAM Children's and Teen Super teen (IMACATS) is one of the non-governmental organisations (NGO) which has adopted this concept to tailor to the local community. The volunteers are healthcare practitioners who are engaged with children in their practice.

Objective: To explore the views of healthcare professional towards TBH by IMACATS in Malaysia.

Methods: In-depth qualitative audio recorded interviews were conducted with a purposive sample of 18 healthcare professionals. The data obtained were transcribed and analysed thematically.

Results: Three themes were derived from the interviews: i) Awareness of the TBH concept. Seven participants have volunteered in TBH previously. However, there was a speculation that many doctors are still unknowing of this concept. ii) Benefits of TBH. This includes reducing children's anxiety, changing children's presumption on healthcare, increasing children's health knowledge and encouraging healthy behaviour and bridging the gap between the public and healthcare. iii) Suggestion of Module for future TBH: (a) More school-based programmes should be organised in addition to hospital and community based; (b) Ministry of Health (MOH) should encourage children health screening using this concept; (c) A module for hospitalised children should be conducted.

Conclusion: Participants interviewed suggested for TBH to be organised in a wider scale as it is an approachable concept for educating children. There are many ways in which it can benefit this community.

Keywords: Teddy Bear Hospital, health education, healthcare professionals, children, Malaysia 